\title{
A duplication of distal Xp associated with hypogonadotrophic hypogonadism, hypoplastic external genitalia, mental retardation, and multiple congenital abnormalities
}

Louise Telvi, Alexandra Ion, Jean-Claude Carel, Isabelle Desguerre, Monique Piraud, Anne Marie Boutin, Josué Feingold, Gérard Ponsot, Marc Fellous, Ken McElreavey

Laboratoire de Cytogénétique, Hôpital Saint Vincent de Paul, 82 avenue Denfert Rochereau, 75674 Paris Cedex 14, France

L Telvi

A Ion

Service

d'Endocrinologie,

Hôpital Saint Vincent de Paul, Paris, France J-C Carel

Service de

Neuropédiatrie,

Hôpital Saint Vincent

de Paul, Paris, France

I Desguerre

G Ponsot

Service de Biochimie, Hôpital Brousse, Lyon,

France

M Piraud

Service de

Neuropédiatrie,

Hôpital La Roche

Guyon, La Roche

Guyon, France

A M Boutin

INSERM U155, Unité d'Epidémiologie Génétique, Paris,

France

J Feingold

\section{Immunogénétique}

Humaine, Institut

Pasteur, Paris, France

$M$ Fellous

K McElreavey

Correspondence to:

Dr Telvi.

Received 7 February 1996 Revised version accepted fo publication 23 April 1996

\begin{abstract}
An unusual familial case of three sibs with a partial duplication of distal $X p$ sequences is described. The proband, an 18 year old boy, showed mental retardation, severe dysmorphic features, hypogonadotrophic hypogonadism (HHG), and hypoplastic external genitalia. His karyotype was 46,Y,inv dup $(X)(p 22.11 \rightarrow p 22.32)$. The proband has two sisters each with the same inv dup (Xp) chromosome. Both sisters presented with short stature but were otherwise phenotypically normal. The abnormal $X$ chromosome was inactive in the majority of cells examined. Southern blot dosage analysis indicated a duplication of distal Xp sequences. The proximal breakpoint is located between DXS28 and DXS41, and is therefore at least $2 \mathrm{Mb}$ distal to the DSS locus. The relationship between the phenotype and the $\mathrm{Xp}$ duplication is discussed.

$(\mp$ Med Genet 1996;33:767-771)
\end{abstract}

Key words: hypogonadotrophic hypogonadism; partial $\mathrm{Xp}$ disomy; mental retardation.

Duplication of distal $\mathrm{Xp}$ sequences is a rare chromosomal rearrangement. In XY subjects, $\mathrm{Xp}$ duplications are usually associated with mental retardation, multiple severe congenital abnormalities, and in some cases $46, \mathrm{XY}$ gonadal dysgenesis, which can lead to female gender assignment. ${ }^{1-910}$ This suggests that two active copies of an $\mathrm{Xp}$ gene in some way inhibit normal testicular determination. An analysis by Bardoni et $a l^{11}$ of $46, \mathrm{XY}$ phenotypic females carrying microscopic and submicroscopic $\mathrm{Xp}$ duplications defined a region of $160 \mathrm{~kb}$ at $\mathrm{Xp} 21.3$ that is associated with male to female sex reversal. This locus, termed DSS (dosage sensitive sex reversal), maps to the same position at $\mathrm{Xp} 21.3$ as the disorder of adrenal gland development, adrenal hypoplasia congenita (AHC). The gene responsible for $\mathrm{X}$ linked AHC and HHG has been recently identified as DAX-1 (DSS-AHC critical region on the $\mathrm{X}$ chromosome, gene 1$) \cdot{ }^{12} \mathrm{DAX}-1$ maps within the DSS interval and encodes a member of the nuclear receptor superfamily. Loss of function mutations of DAX-1 cause both AHC and HHG ${ }^{13}$ Although no gene has been shown to be responsible for male to female sex reversal, DAX-1 is a good candidate gene based on its position and pattern of expression.

We report an unusual familial case of three sibs, one boy and two girls, each harbouring a distal Xp duplication. The karyotype of the boy was 46,Y,inv $\operatorname{dup}(\mathrm{X})(\mathrm{p} 22.11 \rightarrow \mathrm{p} 22.32)$. He presented with multiple congenital abnormalities, mental retardation, hypoplastic external genitalia, and HHG. His sisters were phenotypically normal females except that each presented with short stature. Southern blotting dosage analysis indicated that the boy carried a single copy of the DSS region but was duplicated for $\mathrm{Xp}$ sequences located at least 2 $\mathrm{Mb}$ distal to this position. The DAX-1 open reading frame was sequenced and found to be identical to that of a normal male. Multiple congenital abnormalities and mental retardation may be caused by the presence of two active copies of $\mathrm{Xp}$ genes or alternatively by the disruption of a gene(s) at the duplication breakpoint. Several hypotheses are presented to explain the occurrence of $\mathrm{HHG}$ and hypoplastic external genitalia in the proband: (1) the presence of two active copies of a gene located distal to the DSS region, (2) the disruption of a gene located at the duplication breakpoint, or (3) a possible long range position effect disrupting DSS expression.

\section{Case reports}

The proband was born on 2.2.77 to a 22 year old gravida 2 and her 23 year old husband. The pregnancy was uneventful. At delivery at 41 weeks' gestation, weight, length, and head circumference were $2410 \mathrm{~g}, 45 \mathrm{~cm}$, and $33 \mathrm{~cm}$, respectively.

At 17 years the boy could walk but not speak. He showed profound mental retardation without motor deficit (fig 1). Physical examination showed severe dysmorphic features including microcephaly (-3 SD), long face, blue eyes with mottled irides, downward slanting palpebral fissures, hypertelorism, epicanthus, bilateral ptosis, short eyelashes, bulbous nose, short philtrum, high arched palate, retrognathia, low set ears, low hairline, large and short neck, bulging thorax, low set, widely spaced, retracted nipples, lumbar lordosis, dorsal kyphoscoliosis, and valgus knees. $\mathrm{He}$ had spindle shaped fingers with clinodactyly of the fifth fingers and his feet were flat with bilateral valgal and talocalcaneal fusion. The skin was 
dry and keratotic with congenital cutis laxa and major ligamentous laxity. $\mathrm{He}$ bit his fingers. Axial and limb hypotonia and short stature ( -8 $\mathrm{SD}$ ) were noted (fig 2).

Neurological examination showed a pyramidal syndrome. A CT scan and MRI analysis showed cerebellar cortico-subcortical atrophy. $X$ ray examination showed asymmetry of the pelvis, subluxed femoral heads, and collapse of the tibial condyles. However, there were no signs of chondrodysplasia punctata. The proband had mixed deafness caused by perfo-



Figure 1 The face of the patient at 17 years of age. (Photographs reproduced with consent.)

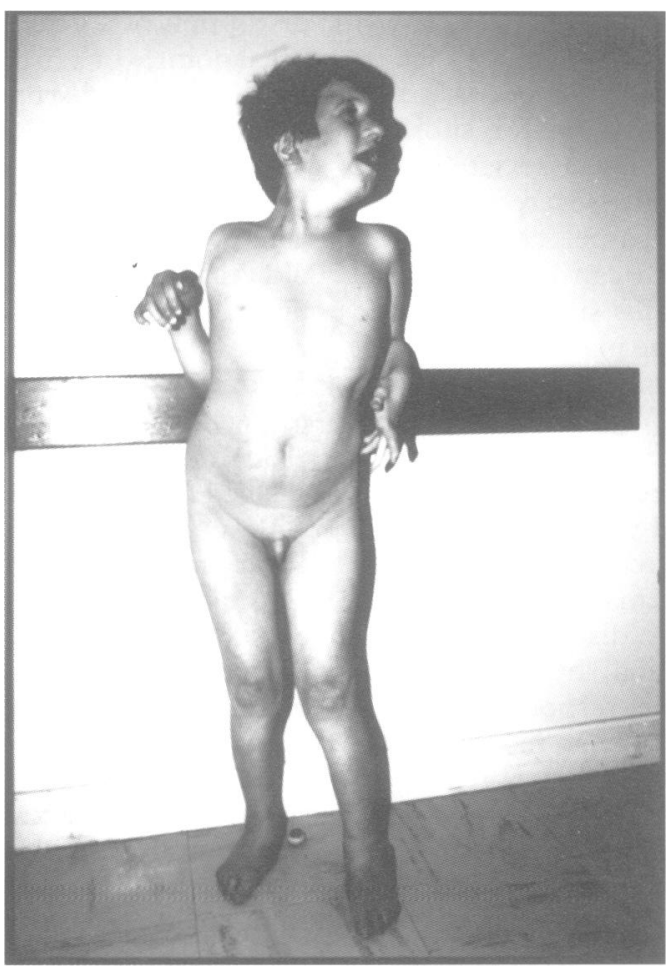

Figure 2 The patient at 17 years of age.
Table 1 The levels of steroid sulphatase activity observed in proband (II.2), his two sisters (II.3, II.4), and his brother (II. 7)

\begin{tabular}{llc}
\hline & STS leucocytes & STS fibroblasts \\
\hline Proband II.2 & 82.3 & 831 \\
Sister II.3 & 39.4 & \\
Sister II.4 & 26.5 & \\
Brother II.7 & 32 & \\
Normal levels in males & $13.9-32.1$ & $175-637$ \\
Normal levels in females & $19.3-40.4$ &
\end{tabular}

The results are expressed in nkat.kg-1.

rated tympanic membranes and lesions of the cochlea. Optical examination showed epiblepharon, cicatricial blepharoconjunctivitis, and pillary coloboma. Cardiac ultrasound showed ballooning of the mitral valve, probably a consequence of the connective tissue hyperextensibility. Electroencephalogram and electromyography were normal.

At 17 years the external genitalia were hypoplastic with a micropenis $(25 \mathrm{~mm})$, left cryptorchidism with inguinal testis, and folding of the scrotal skin. The testes were small $(10 \times$ $7 \mathrm{~mm})$. A pelvic ultrasound showed two kidneys. There was no facial, pubic, or axillary hair.

The two sisters were born in 1978 and 1979, respectively (fig 3 ). They showed short stature $(-3 \mathrm{SD})$ as the only phenotypic abnormality. One of the sisters showed clinical and biological puberty at 13.5 years.

CYTOGENETIC ANALYSIS

Banding patterns were analysed using the RHG and RTBG techniques on chromosomes from lymphocyte cultures. ${ }^{14}$ Chromosome analysis of the proband showed a 46,Y,inv $\operatorname{dup}(\mathrm{X})(\mathrm{p} 22.11 \rightarrow \mathrm{p} 22.32)$ chromosome complement (fig 4). Both sisters II. 3 and II. 4 had the same duplicated $\mathrm{Xp}$ chromosome. Their father (I.2) and their phenotypically normal brother had 46,XY karyotypes. X chromosome replication studies were performed on lymphocytes from II.3 and II.4. The inv $\operatorname{dup}(\mathrm{Xp})$ chromosome was found to be late replicating in 51 out of 52 cells $(98 \%)$ and in 53 out of 55 cells $(96 \%)$ in the two sisters, respectively. The mother was not available for analysis as she had died.

A cell line from the male patient is banked in our department.

ENDOCRINOLOGY

At 17 years the proband had a serum FSH level of $<0.5 \mathrm{IU} / 1$ (normal range 0.6-4.8 IU/l) which rose after administration of LHRH to $1.5 \mathrm{IU} / 1$ (normal 1.2-6.1). Basal LH levels were $<0.5 \mathrm{IU} / 1$ (normal 0.7-2.2 IU/1) and remained undetectable following LHRH stimulation. Testosterone levels rose from $0.3 \mathrm{ng} / \mathrm{ml}$ (normal $1.2-7.0 \mathrm{ng} / \mathrm{ml}$ ) to $2.6 \mathrm{ng} / \mathrm{ml}$ after administration of hCG. Antimullerian hormone level was low for the age of the patient: $1.7 \mathrm{ng} / \mathrm{ml}$ (normal $25 \pm 15 \mathrm{ng} / \mathrm{ml}$ ) (Dr N Josso, Paris). Levels of dehydroepiandrosterone sulphate (SDHA) were found to be normal. Growth hormone $(\mathrm{GH})$ levels were found to be normal before and after ornithine stimulation. 
I II



Figure 3 The pedigree of the family. Affected subjects are indicated by solid symbols.

STEROID SULPHATASE (STS) ACTIVITY

The activity of STS was measured by a radiochemical method using dehydroepiandrosterone sulphate as substrate, according to the technique of Piraud et al. ${ }^{15}$ STS activity, coded by the STS gene located at Xp22.32, was found to be increased in fibroblasts and lymphocytes from the proband. The level of STS in lymphocytes from the two sisters was found to be within the normal range (table 1).

DNA ANALYSIS

The testis determining gene SRY was screened for mutations by both Southern analysis using the probe pY53.3 and by denaturing gradient gel electrophoresis (DGGE), as described elsewhere. ${ }^{16}{ }^{17}$ To determine the extent of the Xp duplication Southern blot dosage analysis was performed using the $\mathrm{Xp}$ probes, from the telomere to the centromere: p782 (DXS85), pdic56 (DXS143), p99.6 (DXS41), C7 (DXS28), QST59 (DXS319:DSS). ${ }^{18}$ The DAX-1 gene was directly sequenced following PCR amplification of genomic DNA. The primers used to amplify and sequence the gene were $1 \mathrm{AF}, 1 \mathrm{AaF}, 1 \mathrm{AaR}, 2875$, and $1 \mathrm{AR}^{7}$ In addition, primers 2AR (GTACCCTTACCCGGG), 2AF (CTCCCTCCAGACGTG), and 2AaR (CAATCAAGTTAATAGTT) were used to amplify and sequence the 3 ' region of the gene. Primer pairs $1 \mathrm{AF}$ and $1 \mathrm{AaR}$ amplify a 764 bp product, 2875 and 2AR a 1004 bp product, and $2 \mathrm{AF}$ and $2 \mathrm{AaR}$ a $621 \mathrm{bp}$ product. Amplified PCR fragments were gel purified and directly sequenced using Sequenase (USB).

Southern blot dosage analysis using Xp probes indicated that the proband carried two copies of the Xp loci DXS85, DXS143, and DXS41. Southern analysis indicated that DXS28 and DXS319 were both present as a single copy (fig 5). The SRY gene was found to be identical to that of a normal male by both Southern blotting (fig 5) and by DGGE analysis (data not shown). The DAX-1 gene was found to have a sequence identical to that of a normal male.

\section{Discussion}

To our knowledge very few cases with a maternal origin of $\operatorname{dup}(\mathrm{Xp})$ have been reported to date. ${ }^{19}$ We identified a familial case with a cytogenetically detectable duplication of the short arm of the X chromosome. Southern blot dosage analysis indicated that the proximal breakpoint of the duplication was located between DXS28 and DXS41. A significant increase in STS activity in cells from the proband also indicated functional disomy of distal Xp. Since the proband had two sisters with the same cytogenetic abnormality, who had short stature as the only phenotypic abnormality, it suggests that the phenotype is caused by the presence of two active copies of gene(s) located at Xp22-23. This hypothesis is supported by the observation that the duplicated $\mathrm{X}$ chromosome was the inactive $\mathrm{X}$ chromosome in the majority of cells examined from the two sisters. STS activity in lymphocytes from each sister was also within the normal range. The DSS region at $\mathrm{Xp} 21.3$ was present as a single copy in the proband. Since DXS28 is located $2 \mathrm{Mb}$ distal to the DSS critical region, the breakpoint must be located at least $2 \mathrm{Mb}$ distal to DSS.

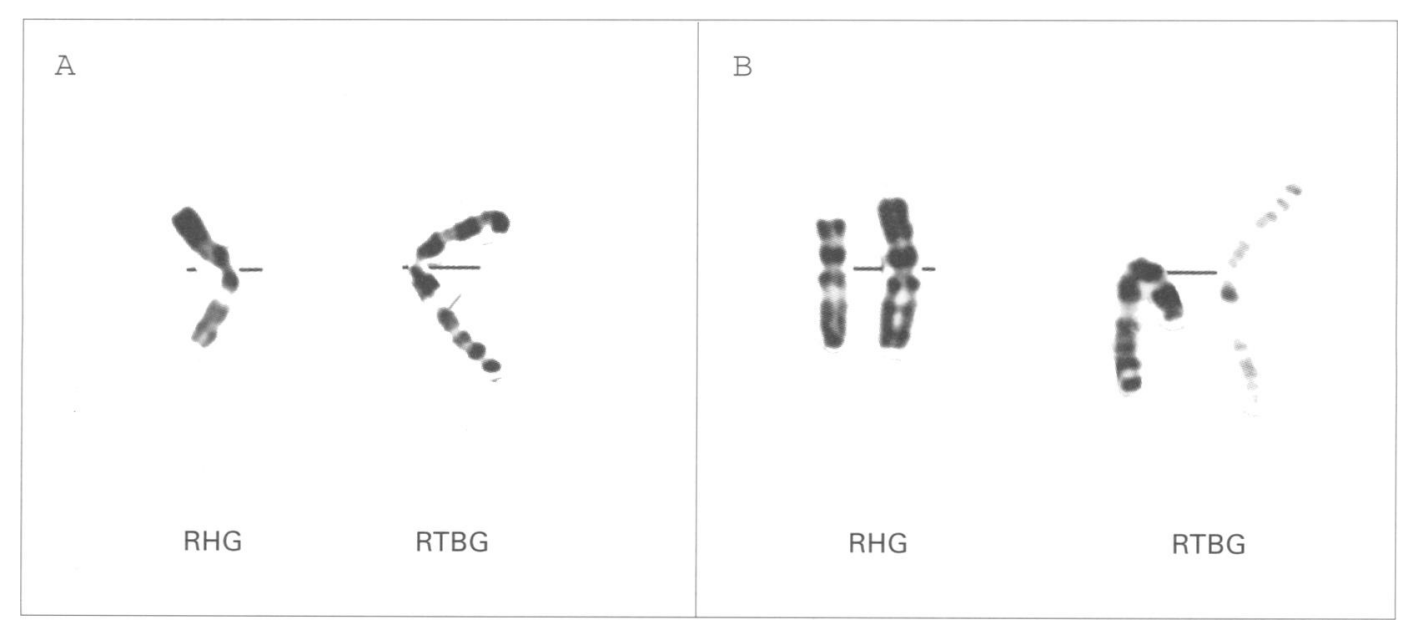

Figure 4 The $X$ chromosomes of the patient and his two sisters showing the rearranged $X$ chromosome after $R H G$ (Reverse-Heat-Giemsa banding) and RTBG (Reverse-Thymidine-BrdU-Giemsa banding). 
Approximately 21 cases of cytogenetically visible duplications of distal $\mathrm{Xp}$ have been reported to date. ${ }^{1-11} 1920$ Both sporadic and familial cases have been described. The duplicated material may be located on the $\mathrm{X}$ chromosome, on an autosome, or on the long arm of the $\mathrm{Y}$ chromosome. Multiple congenital abnormalities and mental retardation have been described in XY subjects carrying an $\mathrm{Xp}$ duplicated fragment. In 11 patients with $\mathrm{Xp} 21.3$ duplication including the DSS region, ambiguous or female external genitalia has been observed, ${ }^{1-4} 7^{2-9}$ and in seven of these cases gonadal dysgenesis was confirmed. ${ }^{148911}$ When analysed, the SRY gene was found to be normal in these subjects.

$46, \mathrm{XY}$ subjects who have duplications of Xp usually present with mental retardation and multiple congenital abnormalities and if the DSS region is duplicated there may also be gonadal dysgenesis. The occurrence of HHG in these cases is rare. There are three possible hypotheses which may explain the presence of HHG and associated hypoplastic external genitalia in our case. First, HHG and associated hypoplastic external genitalia may be caused by two active copies of a gene located at distal Xp. Mutations involving the Kallmann syndrome gene at $\mathrm{Xp} 22$ were associated with HHG and other abnormalities in a $46, \mathrm{XY}$ subject. However, duplications of this gene are unlikely to give rise to $\mathrm{HHG}$ since the majority of subjects with duplications of $\mathrm{Xp}$ including the region of the Kallmann gene have normal FSH and LH levels.

A second hypothesis is that the chromosomal breakpoint of the duplication may
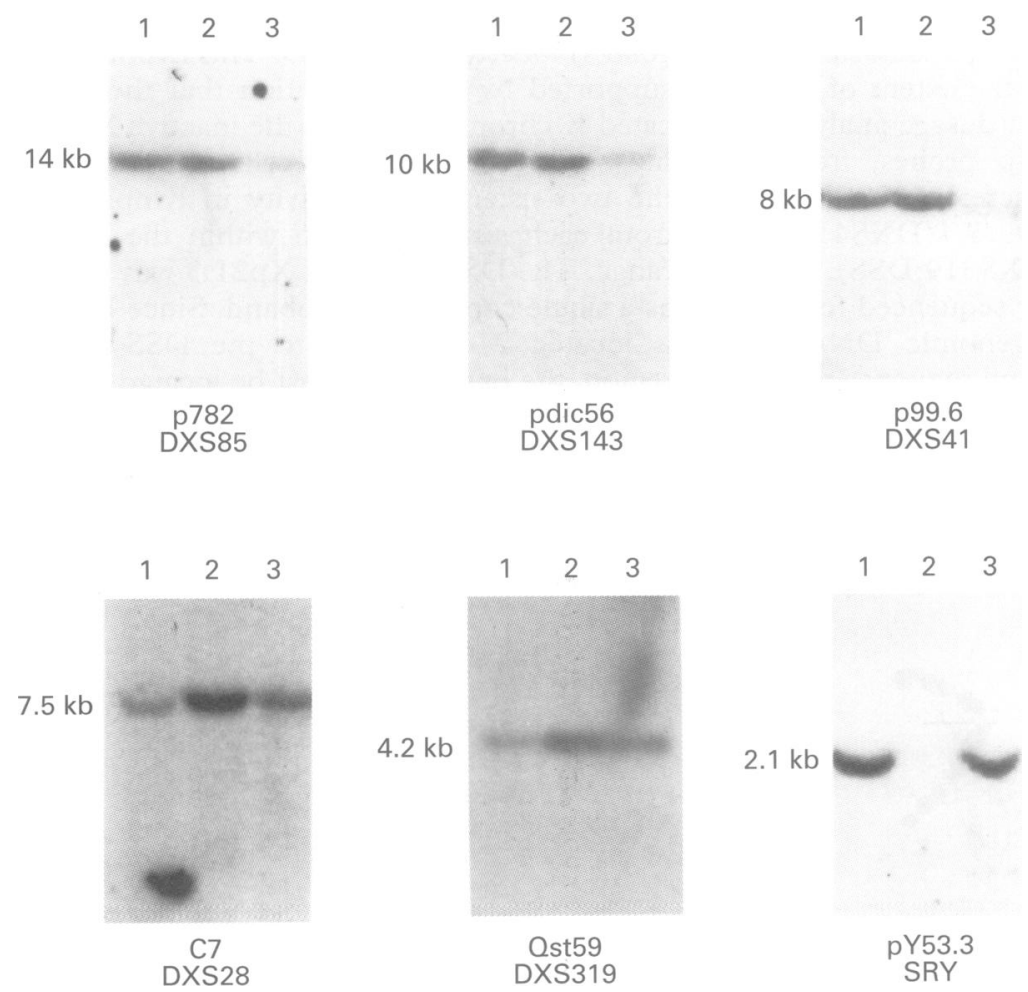

Figure 5 Southern blot dosage analysis of the Xp duplication. The probe and its chromosomal position are indicated. The size of the fragment is shown in kilobases. In each panel lane 1 corresponds to the proband, lane 2 a normal female, and lane 3 a normal male. Genomic DNA was digested with the restriction enzymes MspI ( $p 782, Q s t 59)$, HindIII (pY53.3), EcoRV (C7), BclI (pdic56), or PstI (p99.6). directly interrupt a gene, thereby causing HHG. Bardoni et al described two 46,XY subjects who carried duplications of Xp sequences distal to the DSS region and whose phenotype resembled the boy described in this paper. In one subject (case 4, SR) the external genitalia were hypoplastic and glandular hypospadias was noted. The basal levels of FSH and LH were described as being at the lowest limits of the normal range. The other subject (TM) had hypoplastic external genitalia with cryptorchidism. FSH and LH levels were not indicated. The proximal breakpoint in both cases was located between DXS43 and DXS41, distal to both DSS and DXS28, similar to the breakpoint described in our patient. These data, together with the patient described here, suggest that there might be a gene in this position implicated in the physiology of the gonadotrophins.

Thirdly, it cannot be excluded, in the case presented here, that the duplication may have a silencing effect on a DSS gene located at $\mathrm{Xp} 21.3$. The DAX-1 gene has been mapped within the DSS critical interval. Loss of function mutations in DAX-1 are responsible for the HHG and AHC in a $46, \mathrm{XY}$ subject. ${ }^{12}$ The subject described here had a wild type DAX-1 sequence. In addition Southern analysis failed to detect any abnormality within the DSS interval. It is formally possible that HHG was caused by a long range position effect of the duplication on DAX-1 expression or other genes in the DSS critical region.

The authors wish to thank Chantal Binet, Sylvie Chataignier, and Nicole Souleyreau for excellent technical assistance.

1 Bernstein R, Jenkins T, Dawson B, et al. Female phenotype and multiple abnormalities in sibs with a Y chromosome and partial $\mathrm{X}$ chromosome duplication: $\mathrm{H}-\mathrm{Y}$ antigen and Xg blood group findings. F Med Genet 1980;17:291-300.

2 Scherer G, Schempp W, Baccichetti C, et al. Duplication of an Xp segment that includes the ZFX locus causes sex inversion in man. Hum Genet 1989;81:291-4.

3 Stern HJ, Garrity AM, Seal HM, Wangsa D, Disteche CM. Duplication Xp21 and sex reversal: insight into the mechanism of sex determination. Am $\mathcal{f}$ Hum Genet 1990; 47(suppl):A41.

4 Ogata T, Hawkins JR, Taylor A, Matsuo N, Hata J, Goodfellow PN. Sex reversal in a child with a $46, \mathrm{X}, \mathrm{Yp}+$ low PN. Sex reversal in a child with a 46,X,Yp + karyotype: support for the existence of gene(s), located in
distal Xp, involved in testis formation. $\mathscr{f}$ Med Genet 1992; distal Xp, in $226-30$.

5 Narahara K, Kodama Y, Kimura S, Kimoto H. Probable inverted tandem duplication of $\mathrm{Xp}$ in a $46, \mathrm{Xp}+\mathrm{Y}$ boy. fpn f Hum Genet 1979;24:105-10

6 Nielsen KB, Langkjaer F. Inherited partial X chromosome duplication in a mentally retarded male. $f$ Med Genet 1982;19:222-4

7 May KM, Grizald KA, Blackson RD. Sex reversal and multiple abnormalities due to abnormal segregration of
$\mathrm{t}(\mathrm{X}: 16)(\mathrm{p} 11.4$ :p13.3).Am $\mathfrak{f}$ Hum Genet 1991;49:suppl 19.

$\mathrm{t}(\mathrm{X}: 16)(\mathrm{p} 11.4: \mathrm{p} 13.3)$. Am $\mathcal{f}$ Hum Genet 1991;49:suppl 19.
8 Bardoni B, Floridia G, Guioli S, et al. Functional disomy of Bardoni B, Floridia G, Guioli $S$, et al. Functional disomy of Xp22-pter in three males carrying a portion
cated to Yq. Hum Genet 1993;91:333-8.

9 Arn P, Chen H, Tuck-Muller CM, et al. SRVX, a sex reversing locus in Xp21.2-p22.11. Hum Genet 1994;93:389-93

10 Rao PN, Klinepeter K, Stewart W, Hayworth R, Grubs R, Pettenati MJ. Molecular cytogenetic analysis of a duplication $\mathrm{Xp}$ in a male: further delineation of a possible sex influencing region on the $\mathrm{X}$ chromosome. Hum Genet 1994;94:149-53.

11 Bardoni B, Zanaria E, Guioli S, et al. A dosage sensitive locus at chromosome Xp21 is involved in male to female sex reversal. Nature Genet 1994;7:497-501.

12 Zanaria E, Muscatelli F, Bardoni B, et al. An unusual member of the nuclear hormone receptor superfamily responsible for X-linked adrenal hypoplasia congenita. Nature 1994;372:635-41.

13 Muscatelli F, Strom TM, Walker AP, et al. Mutations in the DAX-1 gene give rise to both X-linked adrenal hypoplasia congenita and hypogonadotropic hypogonadism. Nature 1994;372:672-6. 
14 Telvi L, Bernheim A, Ion A, Fouquet F, Le Bouc Y, Chaussain JL. Gonadal dysgenesis in $\operatorname{del}(18 \mathrm{p})$ syndrome. $A m \mathcal{F}$ Med Genet 1995;57:598-600.

15 Piraud M, Maire I, Zabot MH. X-linked recessive ichthyosis. Enzyme 1989;41:227-34

16 McElreavey $\mathrm{K}$, Vilain $\mathrm{E}$, Abbas $\mathrm{N}$, et al. $\mathrm{XY}$ sex reversal associated with a deletion 5' to the SRY "HMG box" in the testis-determining region. Proc Natl Acad Sci USA 1992;89:11016-20.

17 Sinclair AH, Berta P, Palmer M, et al. A gene from the human sex determining region encodes a protein with Ping region, et al. A gene from with homology to a conserved DNA binding motif. Nature
18 Willard HF, Cremers F, Mandel JL, Monaco AP, Nelson $\mathrm{DL}$, Schlessinger D. Report of the fifth international workshop on human X chromosome mapping 1994. Cytogenet Cell Genet 1994;67:296-351.

19 Cianchetti C, Muntoni F, Falchi AM, et al. X-linked mental retardation and characteristic physical features in two brothers with duplication Xp22-Xpter. Am $\mathcal{F}$ Med Genet 1992;43:475-8.

20 Bajalica S, Blennow E, Tsezou A, et al. Partial disomy of Xp and the presence of SRY in a phenotypic female. $f \mathrm{Med}$ Genet 1995;32:987-90. 